\title{
Editorial
}

\section{Glass-Ceramics: Improving Glass Properties through Crystallization}

\author{
Araceli De Pablos Martin 1,*(D) and Giulio Gorni ${ }^{2, *(D)}$ \\ 1 Otto Schott Institute of Materials Research, Friedrich Schiller University Jena, Fürstengraben 1, \\ 07743 Jena, Germany \\ 2 CELLS-ALBA Synchrotron, Carrer de la Llum 2-26, 08290 Cerdanyola del Vallès, Spain \\ * Correspondence: araceli.de.pablos.martin@uni-jena.de (A.D.P.M.); ggorni@cells.es (G.G.)
}

Citation: De Pablos Martin, A.;

Gorni, G. Glass-Ceramics: Improving

Glass Properties through

Crystallization. Crystals 2021, 11, 1084 https://doi.org/10.3390/cryst11091084

Received: 2 September 2021

Accepted: 3 September 2021

Published: 7 September 2021

Publisher's Note: MDPI stays neutral with regard to jurisdictional claims in published maps and institutional affiliations.

Copyright: (c) 2021 by the authors. Licensee MDPI, Basel, Switzerland. This article is an open access article distributed under the terms and conditions of the Creative Commons Attribution (CC BY) license (https:// creativecommons.org/licenses/by/ $4.0 /)$.
Controlled crystallization of glasses is a broad research area within glass science in which researchers from academia and industry are both involved. Commercial and wellestablished glass-ceramics are used for optical, technological and biological applications. However, there are still a number of open questions and further research is needed.

The aim of this Special Issue is to highlight the role of controlled crystallization of glasses to produce glass-ceramics with optimized properties compared to the parent glasses.

Authors from academia (including universities and research centers) and industry from many different countries contributed to this Special Issue: Spain, Romania, Uruguay and Japan. They show the wide range of research in this field worldwide, but also in terms of applications, glass compositions, characterization techniques and properties of interest.

The contributions in the Special Issue cover two of the most important application areas of glass ceramics: optical and technological. The optical, mechanical and rheological properties have been evaluated as a function of the degree of crystallization. In addition, this Special Issue contains papers where the two most common glass-manufacturing processes are described: the melt-quenching and sol-gel methods.

Within glass-ceramics for optical applications, two published papers report on fluoride crystalline phases. The work by Rodriguez-Chialanza et al. [1] describes the preparation and characterization of a series of glass-ceramics that exhibit thermoluminescence. Here, the chemical composition was adjusted by varying the $\mathrm{NaF}$ content to obtain $\mathrm{BaF}_{2}$ nanocrystals embedded in a borate matrix with optimized thermoluminescent properties. A continuous trap distribution was obtained, making this material promising for use as a radiation sensor or in spectral converters. The second published work on this field is that of Cruz et al. [2], which shows the nanocrystallization of $\mathrm{LaF}_{3}$ and $\mathrm{NaLaF}_{4} \mathrm{in}_{\mathrm{SiO}_{2}}$ matrices prepared by the sol-gel route. In addition to $\mathrm{LaF}_{3}, \mathrm{NaLaF}_{4}$ crystallizes only at the highest treatment temperature and the $\mathrm{NaLaF}_{4}$ crystal fraction was changed by tuning the amount of $\mathrm{Na}$. In this work, high-resolution transmission electron microscopy was used to verify the nanometer size of the crystals (below $50 \mathrm{~nm}$ ) and their size distribution. The incorporation of $\mathrm{Nd}^{3+}$ ions into $\mathrm{NaLaF}_{4}$ and $\mathrm{LaF}_{3}$ nanocrystals was clearly confirmed by site-selective emission and excitation spectra and a much higher photoluminescent emission is achieved for $\mathrm{Nd}^{3+}$ ions embedded in $\mathrm{NaLaF}_{4}$ nanocrystals.

Another study on glass-ceramics for optical applications is that of Secu et al. [3], which reports $\mathrm{BaCl}_{2}$ nanocrystals in a borate matrix. Interestingly, the added $\mathrm{Eu}^{3+}$ dopant ions convert partially into $\mathrm{Eu}^{2+}$ after heat treatment in reducing atmosphere and $\mathrm{Eu}^{3+}$ ions remain mostly in the glassy matrix while part of $\mathrm{Eu}^{2+}$ ions are incorporated into the $\mathrm{BaCl}_{2}$ crystals. The advantages of glass-ceramics are revealed by the increased photoluminescent response compared to glasses. The authors also pointed out how the glass-ceramics offer a viable solution to overcome the disadvantages of the $\mathrm{BaCl}_{2}$ crystal phosphor.

A completely different application is provided in the paper authored by RodriguezLopez [4] that describes glass-ceramics for solid oxide fuel cells (SOFCs) in the system $\mathrm{BaO} / \mathrm{SrO}-\mathrm{MgO}-\mathrm{B}_{2} \mathrm{O}_{3}-\mathrm{SiO}_{2}$. In order to investigate the sintering and crystallization behavior of the glasses, a comprehensive thermal characterization was carried out, including: 
differential thermal analysis, hot stage microscopy, dilatometry and viscosity measurements using a beam bending viscometer. Composition, particle size and thermal properties were optimized for SOFC operating conditions. The slower crystallization rate of the strontium-containing glass composition results in good joining with the interconnect steel before the glass starts to crystallize and increases its viscosity.

Finally, this Special Issue also contains a review paper [5] by authors from industry and academia who report on a comparative study of the mechanical properties of glass-ceramics, typically studied for their mechanical performance. The review presents new results on a glass-ceramic with high fracture toughness in the system $\mathrm{CaO}-\mathrm{Al}_{2} \mathrm{O}_{3}-\mathrm{SiO}_{2}$ (CAS). The fracture behavior of these CAS glass-ceramics was compared with that of enstatite and mica glass-ceramics, which are well-known examples of glass-ceramic materials with highfracture toughness and machinability, respectively. The non-elastic behavior of the CAS glass-ceramic was attributed to microcrack formation due to the cleavage characteristics of the hexagonal $\mathrm{CaAl}_{2} \mathrm{Si}_{2} \mathrm{O}_{8}$ crystals formed during a controlled crystallization of the parent glass. The CAS glass-ceramic described in this paper is characterized by a lower brittleness, similar to machinable mica glass-ceramic, but with higher fracture toughness.

The results included in this Special Issue on "Glass-Ceramics: Improving Glass Properties through Crystallization" point out the important benefits obtained by a proper design of the glass composition followed by a controlled crystallization of the glass in order to get the desired crystals. The improvement of specific properties compared to glasses is strongly associated with the phase, size and amount of the crystals grown in the glass matrix. Although almost seventy years have passed since the preparation of the first glass-ceramics, these materials are still a hot topic with growing interest in the glass science community and with applications covering many relevant technological fields.

Funding: This research received no external funding.

Conflicts of Interest: The authors declare no conflict of interest.

\section{References}

1. Rodríguez-Chialanza, M.; Azcune, G.; Bentos Pereira, H.; Faccio, R. New Perspective on Thermally Stimulated Luminescence and Crystallization of Barium Borate Oxyfluoride Glasses. Crystals 2021, 11, 745. [CrossRef]

2. Cruz, M.; Li, J.; Gorni, G.; Durán, A.; Mather, G.; Balda, R.; Fernánndez, J.; Castro, Y. Crystallization Process and Site-Selective Excitation of $\mathrm{Nd}^{3+}$ in $\mathrm{LaF}_{3} / \mathrm{NaLaF}_{4}$ Sol-Gel-Synthesized Transparent Glass-Ceramics. Crystals 2021, 11, 464. [CrossRef]

3. Secu, M.; Secu, C. Processing and Optical Properties of Eu-Doped Chloroborate Glass-Ceramic. Crystals 2020, 10, 1101. [CrossRef]

4. Rodríguez-López, S.; Pascual, M. Sintering/Crystallization and Viscosity of Sealing Glass-Ceramics. Crystals 2021, 11, 737. [CrossRef]

5. Maeda, K.; Akatsuka, K.; Okuma, G.; Yasumori, A. Mechanical Properties of $\mathrm{CaO}-\mathrm{Al}_{2} \mathrm{O}_{3}-\mathrm{SiO}_{2}$ Glass-Ceramics Precipitating Hexagonal $\mathrm{CaAl}_{2} \mathrm{Si}_{2} \mathrm{O}_{8}$ Crystals. Crystals 2021, 11, 393. [CrossRef] 